\title{
Retinopathy of prematurity in Rwanda: a prospective multi-centre study following introduction of screening and treatment services
}

\author{
Francis Mutangana ${ }^{1} \cdot$ Charles Muhizi $^{2} \cdot$ Godelieve Mudereva $^{3} \cdot$ Piet Noë $^{4} \cdot$ Stephenson Musiime $^{5}$. \\ Tharcisse Ngambe $^{5} \cdot$ Lisine Tuyisenge $^{6} \cdot$ Muzungu Kumwami $^{6} \cdot$ Hovaire Nsabimana $^{7}$. Craig Conard . $^{7}$ \\ Yannick Fonteyne ${ }^{8} \cdot$ Ingele Casteels $^{9} \cdot$ Stefan De Smedt $^{10} \cdot$ for the Rwanda Retinopathy of Prematurity Study Group
}

Received: 3 October 2018 / Revised: 5 April 2019 / Accepted: 18 June 2019 / Published online: 30 July 2019

(c) The Author(s), under exclusive licence to The Royal College of Ophthalmologists 2019

\begin{abstract}
Objectives To investigate risk factors for retinopathy of prematurity (ROP) in a newly established ROP screening and management programme in Rwanda, Africa.

Methods In this multi-centre prospective study 795/2222 (36\%) babies fulfilled the inclusion criteria (gestational age (GA) $<35$ weeks or birth weight (BW) $<1800 \mathrm{~g}$ or unstable clinical course), $424(53 \%)$ of whom were screened for ROP. 270 died before the first screening. ROP and treatment-warranted ROP were classified using the revised International Classification of ROP (2005). Data on maternal and perinatal risk factors were collected from daily neonatal notes.

Results 31 babies (7.3\%, CI 5.0-10.2) developed any ROP, 13 of whom (41.9\%, CI 24.5-60.9) required treatment. ROP was seen in six neonates with GA $>30$ weeks and $\mathrm{BW}>1500 \mathrm{~g}$, one of whom required treatment. In univariate analysis the following were associated with any ROP: increasing number of days on supplemental oxygen (OR 2.1, CI 1.5-3.0, $P<$ 0.001), low GA (OR 3.4, CI 1.8-6.4, $P<0.001$ ), low BW (OR 2.3, CI 1.5-3.4, $P<0.001$ ), at least one episode of hyperglycaemia $\geq 150 \mathrm{mg} / \mathrm{dl}$ (OR 6.6, CI 2.0-21.5, $P<0.001$ ), blood transfusion (OR 3.5, CI 1.6-7.4, $P<0.001$ ) or sepsis (OR 3.2, CI 1.2-8.6, $P=0.01$ ). In multivariate analysis longer exposure to supplemental oxygen (OR 2.1, CI 1.2-3.6, $P=$ $0.01)$ and hyperglycaemia (OR 3.5, CI 1.0-12.4, $P=0.05$ ) remained significant.

Conclusions ROP has become an emerging health problem in Rwanda, requiring programmes for screening and treatment. ROP screening is indicated beyond the 2013 American Academy guidelines. Improved quality of neonatal care, particularly oxygen delivery and monitoring is needed.
\end{abstract}

These authors contributed equally: Francis Mutangana, Charles Muhizi

Meeting presentation: The work has been accepted and presented as Poster Presentation (Poster 186-B0340, abstract \#2906642) for the 2018 ARVO Annual Meeting in Honolulu.

Supplementary information The online version of this article (https:// doi.org/10.1038/s41433-019-0529-5) contains supplementary material, which is available to authorised users.

Stefan De Smedt, MD PhD

dr.stefan.desmedt@gmail.com

1 Ophthalmology, King Faisal Hospital, Kigali, Rwanda

2 Ophthalmology, CHUB, Huye, Rwanda

3 Ophthalmology, CHUK, Kigali, Rwanda

4 Ophthalmology, Kabgayi Eye Hospital, Rwanda Charity Eye Hospital, Southern Province, Rwanda

\section{Introduction}

Retinopathy of prematurity (ROP) is a potentially blinding eye condition, associated with abnormal retinal vascular proliferation at the boundary of vascularised and avascular peripheral retina of prematurely born babies. This can lead to retinal detachment and visual loss [1]. Regular screening and timely treatment are essential in improving anatomical and functional outcomes and should be part of routine

\footnotetext{
Pediatrics, King Faisal Hospital, Kigali, Rwanda

6 Pediatrics, CHUK, Kigali, Rwanda

7 Pediatrics, CHUB, Huye, Rwanda

8 External consultant, Mechelen, Belgium

9 Ophthalmology, KU Leuven, Leuven, Belgium

10 Ophthalmology, Epidemiology, AZ St Maarten Hospital, Mechelen, Belgium
} 
neonatal care. During the 1940/50s and 1970s a first and a second epidemic of ROP blindness affected preterm babies in high-income countries and these were associated with the widespread use of unrestricted oxygen supplementation and increasing survival of infants at lower gestational age (GA) (< 28 weeks), respectively.

In the 1990s a third epidemic of blindness due to ROP was described, principally in the middle and low income countries of Latin America, Eastern Europe, and later Asia [2]. In 2010, an estimated 184,700 preterm infants worldwide developed any stage of ROP, and more than 30,000 became visually impaired due to ROP [3]. In these middle income countries neonatal care is rapidly expanding, leading to greater survival of more immature, small for GA, and low-birth weight infants $[2,4]$. In addition, suboptimal neonatal care, as a result of lack of awareness and resources, can lead to higher rates of severe ROP not only in extremely premature infants but also in larger, more mature infants $[5,6]$.

In sub-Saharan Africa, little is known about the incidence of ROP [7-11]. A recent worldwide survey indicated that ROP screening is very limited in Africa [12]. In Rwanda, major advances in the survival of preterm infants have occurred recently due to improving neonatal care [13]. As a consequence, more extremely preterm infants are at risk of ROP. The recent presentation of several children born preterm with bilateral inoperable retinal detachment to an Ophthalmology Department in Rwanda prompted us to set up a screening system. A prospective observational study to document the incidence and risk factors for ROP was undertaken in Rwanda's three major neonatal intensive care units (NICU) with level 2 neonatal care (i.e. limited access to ventilation and no total parental nutrition).

\section{Subjects and methods}

A risk factor study was nested within the prospective observational study carried out in the NICUs of three tertiary hospitals in Rwanda from September 2015 to July 2017. Two NICUs were located in the capital city Kigali, i.e. King Faisal Hospital (KFH) and University Teaching Hospital of Kigali (CHUK), and one in Huye, University Teaching Hospital of Huye (University of Rwanda campus Butare, CHUB).The study population were all preterm babies admitted to these NICUs who fulfilled the inclusion criteria, i.e. $\mathrm{GA}<35$ weeks or birth weight $(\mathrm{BW})<1800$ grams (g) or an unstable clinical course, as indicated by the paediatrician.

\section{Data management}

Data on potential risk factors were extracted from daily neonatal progress notes throughout hospital admission on a weekly basis. BW and GA were defined as categorical variables. Exposure to supplemental oxygen was assessed as the number of days in supplemental oxygen (categorical variable) and method of administration, i.e. nasal cannula, continuous positive airway pressure (CPAP) or ventilator [10]. In cases of nasal cannula, supplemental unblended oxygen was delivered. Initially oxygen saturation was recorded but was felt to be too unreliable as a study variable. Sepsis was defined as early or late (starting 3 or more days after birth), necessitating antibiotic treatment for $\geq 5$ days on clinical grounds and/or on the basis of a positive blood culture, if available. Blood transfusion was defined as the administration of adult red blood cells on one or more occasions. Hyperglycaemia was defined as serum glycemia $\geq 150 \mathrm{mg} / \mathrm{dl}$ sampled before a meal.

The first eye examination took place 4 weeks after birth. At the beginning of the study six local ophthalmologists were trained in ROP screening by an expert ophthalmologist during joint screening sessions. Quality control on the screening process took place during follow-up visits. Both monocular and binocular indirect ophthalmoscopy were performed using a 20 or 30 dioptre lens and indentation or Missotten-Fabri neonatal lens (Fabrilens, Lommel, Belgium), depending on the preference of the attending ophthalmologist. This lens serves both as a magnifier and speculum to keep the eyelids open. Retinal changes were classified by stage, zones and the presence of plus disease using standard photographs based on the International Classification of ROP and Early Treatment for ROP studies $[14,15]$.

The maximum severity of ROP in either eye was the level assigned to each infant. ROP-screening was at least every 2 weeks until vascularisation reached zone III or until 41 weeks postmenstrual age. Weekly screening was scheduled if the vessels ended in zone I or posterior zone II, or if there was any plus disease, or any stage 3 disease in any zone. Treatment-warranted ROP (TW-ROP) was defined Type 1 ROP i.e. ROP in Zone I, stage 3 without plus disease or in Zone I, any stage with plus disease, or ROP in Zone II, Stage 2 and 3 with plus disease [15].

\section{Statistical analysis}

Data were entered into a Microsoft Access database and analysed using STATA-software 9.2 (STATA Corp, College Station, TX). Statistics were presented overall and for the subgroups any ROP, TW-ROP and no ROP. Statistical analysis compared infants with any ROP with those without. Further analysis compared infants with TW-ROP with those without ROP. Potential risk factors were evaluated in univariate logistic regression analyses calculating odds ratios (OR) and $95 \%$ confidence intervals (CI) at 0.05 level of significance. Variables which were statistically 
significant were entered into a multivariate logistic regression model using a backward stepwise method. Assuming a prevalence of any ROP of $15 \%$ among exposed and $5 \%$ among non-exposed to potential risk factor, a sample size of at least 380 babies was needed to achieve $90 \%$ power at the $5 \%$ level of significance.

\section{Ethics}

The study was conducted in accordance with the Declaration of Helsinki and was approved by the Rwandan National Ethics Committee. An information sheet was read out to parents/caregivers in Kinyarwanda, after which they signed a consent form. All medical eye care related to ROP was provided free of charge. This densely populated country with a reasonably good main infrastructure has a compulsory health insurance system, which facilitates access to health care even for the poor.

\section{Results}

\section{Study population}

Among 2222 babies admitted to the NICUs, 795 (35.8\%) fulfilled the criteria for ROP screening, 424 (53\%) of whom were screened. Among the 371 not screened, 270 died before the first screening, 89 were lost to follow-up after discharge and 12 carers refused to participate.

Among the 424 screened, 370 (87.3\%) babies completed the screening process, 5 had any ROP documented when they were lost to follow-up, and 49 were still ROP negative when lost to follow-up before vascularisation reached zone III or 41 weeks postmenstrual age. Of those 49 babies 3 died prior to the second eye screening and 28 were seen twice or more.

A total of 31 babies (7.3\%, CI 5.0-10.2) developed any ROP, 13 of whom (41.9\%, CI 24.5-60.9) required treatment i.e., 3.1\% (CI 1.6-5.2) of all babies screened. The demographic and pregnancy characteristics of the premature babies screened are presented in Table 1 . There were no sex differences among babies eligible for screening and those screened $(P=0.93$ and 0.58 respectively). Most babies $(n=279)$ were delivered by Caesarean section $(67.7 \%)$ and $365(87.7 \%)$ were born in the same hospital as the NICU. The mean age of mothers of babies with ROP tended to be higher than of babies without (mean 31.9 years (SD 6.4, range 18-41) and mean 30.1 years (SD 5.9, range 18-48) respectively) (Table 1 ).

The mean GA of those screened was 31.7 weeks (SD 2.2 , range 24-37) overall and 30.1 weeks (SD 2.4, range 25-36) in the ROP group. The mean BW was $1479 \mathrm{~g}$ (SD 360.1, range 650-2800) overall and $1199 \mathrm{~g}$ (SD 303.3, range 685-1800) in the ROP group (Table 1). ROP was seen in six babies with GA $>30$ weeks and $\mathrm{BW}>1500 \mathrm{~g}$ (19.4\% of ROP-cases), one of whom required treatment (GA 32 weeks with BW $1600 \mathrm{~g}$ ) (Fig. 1). The neonatal and clinical data of the babies screened are presented in Tables 2 and 3. Sepsis occurred in 264 babies $(63.6 \%)$ overall and in 26 babies $(83.9 \%)$ in the ROP group. A serum glucose test was available for $151 / 424(35.6 \%)$ babies, as it was only routinely performed in one NICU. Hyperglycaemia $(\geq 150 \mathrm{mg} / \mathrm{dl})$ was documented in 28 babies $(18.5 \%)$ overall and in eight babies with ROP $(53.3 \%)$. Supplemental oxygen was given to 279 babies $(67.6 \%)$ overall and 27 babies $(87.1 \%)$ in the ROP group. Blood transfusion was needed in 117 babies $(28.1 \%)$ overall and 17 babies $(54.8 \%)$ in the ROP group. Babies not completing the screening process were not significantly different in terms of BW, GA or any other relevant risk factor for ROP. The 89 babies who did not attend for the first screening were similar, except for a significantly lower birth weight $(P<0.001)$.

\section{Risk factors for any ROP}

Univariate analysis comparing infants with any ROP with those without identified the following risk factors: days in oxygen (OR 2.1, CI 1.5-3.0, $P<0.001$ ), low GA (OR 3.4, CI 1.8-6.4, $P<0.001$ ), low BW (OR 2.3, CI 1.5-3.4, $P<$ 0.001 ), hyperglycaemia (OR 6.6, CI 2.0-21.5, $P<0.001$ ), blood transfusion (OR 3.5, CI 1.6-7.4, $P<0.001$ ) and sepsis (OR 3.2, CI 1.2-8.6, $P=0.01$ ) (Table 4). The APGAR-scores at 1,5 and $10 \mathrm{~min}$ after birth were not significantly associated with ROP. There was evidence of a dose-response effect with increasing prematurity, low birth weight and days in supplemental oxygen (test for trend for each variable, $P<0.001)$. Oxygen administration using nasal cannula was associated with ROP $(P<$ $0.001)$ but not administration via CPAP $(P=0.63)$. The onset of sepsis did not significantly affect the incidence of any $\operatorname{ROP}(P=0.79)$. In the multivariate logistic regression model, days in oxygen (OR 2.1, CI 1.2-3.6, $P=$ 0.01 ) and hyperglycaemia (OR 3.5, CI 1.0-12.4, $P=$ $0.05)$ were the only factors that remained significant for any ROP. Because BW and GA were highly correlated $(P<0.001)$, a combined summary variable including both was created, which was of borderline significance in this multivariate model (OR 1.5, CI 1.0-2.2, $P=0.06$ ). Days in supplemental oxygen (OR 1.7, CI 1.2-2.6, $P=0.007$ ) remained significant but hyperglycaemia did not. No statistically significant interactions between the retained variables were identified, nor was there evidence of a weak fit for the overall models (Pearson chi $^{2}$ test $=3.53$, $P=0.62$ and Pearson chi $^{2}$ test $=11.97, \quad P=0.75$, respectively). 
Table 1 Demographic and pregnancy characteristics of the premature babies screened for retinopathy of prematurity $(n=424)$

\begin{tabular}{|c|c|c|c|c|c|c|c|c|c|c|c|c|}
\hline & \multicolumn{3}{|l|}{ All infants } & \multicolumn{3}{|l|}{ No ROP } & \multicolumn{3}{|l|}{ Any ROP } & \multicolumn{3}{|c|}{$\begin{array}{l}\text { Treatment- } \\
\text { warranted ROP }\end{array}$} \\
\hline & Missing data & $n$ & $\%$ & Missing data & $n$ & $\%$ & Missing data & $n$ & $\%$ & Missing data & $n$ & $\%$ \\
\hline Primipara & 9 & 130 & 31.3 & 9 & 123 & 32.0 & & 7 & 22.6 & & 3 & 23.1 \\
\hline Received antenatal steroid & 11 & 263 & 63.7 & 10 & 243 & 63.5 & 1 & 20 & 66.7 & 1 & 6 & 50.0 \\
\hline Positive HIV status mother & 39 & 6 & 1.6 & 35 & 6 & 1.7 & 2 & 0 & 0.0 & 2 & 0 & 0.0 \\
\hline Method of delivery & 12 & & & 12 & & & & & & & & \\
\hline Caesarean section & & 279 & 67.7 & & 263 & 69.0 & & 16 & 51.6 & & 4 & 30.8 \\
\hline Forceps/ventouse aided delivery & & 0 & 0.0 & & 0 & 0.0 & & 0 & 0.0 & & 0 & 0.0 \\
\hline unaided normal delivery & & 133 & 32.3 & & 118 & 31.0 & & 15 & 48.4 & & 9 & 69.2 \\
\hline Sex of the baby & 7 & & & 7 & & & & & & & & \\
\hline Male & & 192 & 46.0 & & 180 & 46.6 & & 12 & 38.7 & & 3 & 23.1 \\
\hline Female & & 225 & 54.0 & & 206 & 53.4 & & 19 & 61.3 & & 10 & 76.9 \\
\hline No. of gestations & 8 & & & 8 & & & & & & & & \\
\hline Singleton & & 304 & 73.1 & & 280 & 72.7 & & 24 & 77.4 & & 9 & 69.2 \\
\hline Twins & & 85 & 20.4 & & 78 & 20.3 & & 7 & 22.6 & & 4 & 30.8 \\
\hline Triplets & & 27 & 6.5 & & 27 & 7.0 & & 0 & 0.0 & & 0 & 0.0 \\
\hline Place of birth & 8 & & & 8 & & & & & & & & \\
\hline At home & & 2 & 0.5 & & 2 & 0.5 & & 0 & 0.0 & & 0 & 0.0 \\
\hline In health centre & & 3 & 0.7 & & 3 & 0.8 & & 0 & 0.0 & & 0 & 0.0 \\
\hline In hospital of NICU & & 365 & 87.7 & & 341 & 88.6 & & 24 & 77.4 & & 11 & 84.6 \\
\hline In other hospital & & 46 & 11.1 & & 39 & 10.1 & & 7 & 22.6 & & 2 & 15.4 \\
\hline Gestational age (weeks) & 7 & & & 7 & & & & & & & & \\
\hline$<26$ & & 3 & 0.7 & & 2 & 0.5 & & 1 & 3.2 & & 1 & 7.7 \\
\hline 26 to $<28$ & & 15 & 3.6 & & 13 & 3.4 & & 2 & 6.5 & & 0 & 0.0 \\
\hline 28 to $<30$ & & 49 & 11.8 & & 38 & 9.8 & & 11 & 35.5 & & 3 & 23.1 \\
\hline 30 to $<32$ & & 106 & 25.4 & & 97 & 25.1 & & 9 & 29.0 & & 5 & 38.5 \\
\hline 32 to $<35$ & & 225 & 54.0 & & 218 & 56.5 & & 7 & 22.6 & & 4 & 30.8 \\
\hline$\geq 35$ & & 19 & 4.6 & & 18 & 4.7 & & 1 & 3.2 & & 0 & 0.0 \\
\hline Birth weight (g) & 9 & & & 9 & & & & & & & & \\
\hline$<1000$ & & 31 & 7.5 & & 23 & 6.0 & & 8 & 25.8 & & 4 & 30.8 \\
\hline 1000 to $<1500$ & & 191 & 46.0 & & 175 & 45.6 & & 16 & 51.6 & & 8 & 61.5 \\
\hline 1500 to $<1800$ & & 115 & 27.7 & & 109 & 28.4 & & 6 & 19.4 & & 1 & 7.7 \\
\hline$\geq 1800$ & & 78 & 18.8 & & 77 & 20.1 & & 1 & 3.2 & & 0 & 0.0 \\
\hline
\end{tabular}

$R O P$ retinopathy of prematurity

\section{Risk factors for treatment-warranted ROP}

Univariate analysis identified the following risk factors for TW-ROP: low BW (OR 5.7, CI 2.3-13.9, $P<0.001$ ), blood transfusion (OR 3.3, CI 1.1-10.2, $P=0.03)$, sepsis $(P=$ 0.005 ) and some categories of low GA (OR 3.5, CI $1.0-11.9, P=0.03)$ (Table 5 in supplement).

Caesarean section was protective against TW-ROP (OR 0.2 , CI $0.06-0.67, P=0.004$ ). Decreasing birth weight was associated with TW-ROP (score test for trend of odds $P=0.005)$. The onset of sepsis did not influence the incidence of TW-ROP $(P=0.43)$. In multivariate analysis the combined variable for $\mathrm{BW}$ and GA was an independent risk factor (OR 2.1, CI 1.3-3.6, $P=0.002$ ), and Caesarean section remained protective (OR 0.2, CI $0.06-0.71, P=0.01)$.

\section{Discussion}

Until the late 20th century blindness from ROP was virtually unknown in sub-Saharan Africa, apart from South Africa where ROP accounted for $11 \%$ of blindness in children in 1996 [5, 16]. In 1995 an early Nigerian study found no TW-ROP, but 5.6\% had any ROP [17]. A high proportion of affected babies in this study died [17]. 


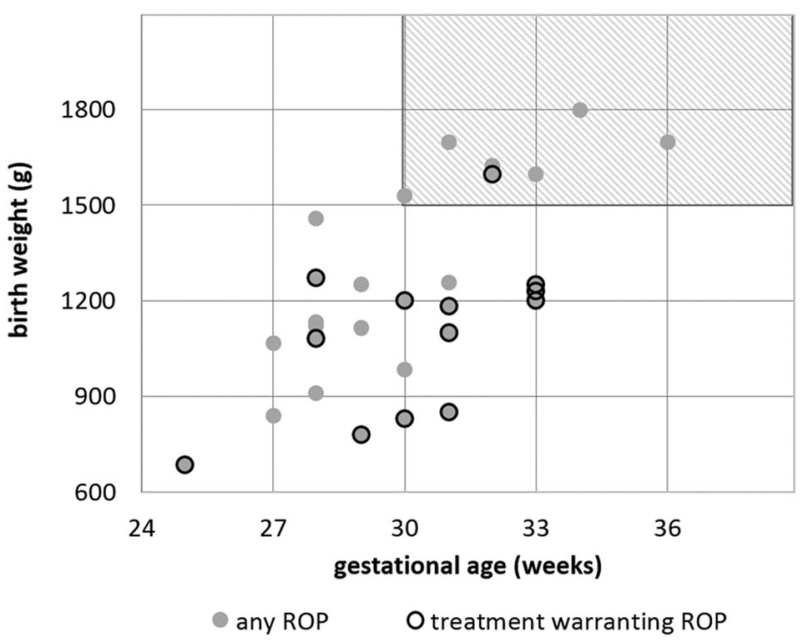

Fig. 1 Distribution of retinopathy of prematurity (ROP) cases by birth weight (BW) and gestational age (GA). The grey area represents BW and GA beyond the American Academy 2013 screening criteria (BW $\leq 1500 \mathrm{~g}$ and $\mathrm{GA} \leq 30$ weeks)

However, over the last decade NICU services have expanded in sub-Saharan Africa, to help achieve Goal 4 of the U.N. Millennium Development Goals (reduction of under 5-mortality rate) [13]. Therefore, ROP is expected to have increased, but there are limited recent data on ROP apart from studies in South Africa [9, 10, 18, 19] and Nigeria $[11,20]$.

The proportion of infants screened who developed TWROP $(3.1 \%)$ in our study is similar to that reported from other lower and middle-income settings (1-7.1\%) $[8,11,18]$, but the percentage developing any ROP $(7.3 \%)$ was lower $(15-47.2 \%)[8,9,11,19,20]$. Differences in patient selection, examination methods, and survival rates of premature babies between low and middle-income countries can partly explain this discrepancy [5, 9, 20, 21], Clinically non-significant ROP stages might also have been underreported in our study because of a learning curve while setting up a screening programme.

Infants with ROP in our study had more days in oxygen, lower BW, lower GA, more episodes of hyperglycaemia and sepsis and needed more blood transfusions than those without, similar to findings in other lower and middleincome country studies [9].

In our study, oxygen - expressed as the number of days of supplementation-remained a significant risk factor in multivariate analysis. Several studies from middle-income countries failed to identify oxygen exposure as an independent risk factor $[9,22,23]$, while others have shown that improved oxygen delivery and adequate saturation targeting and monitoring in infants receiving oxygen can effectively decrease the incidence of ROP, even in rural areas [18, 24]. Assessing oxygen exposure reliably requires collecting accurate, continuous data on oxygen saturations-which is difficult to capture. Fluctuation in saturation levels is also important [25], and in our study settings it was not possible to document oxygen saturations reliably. A recent prospectively planned meta-analysis of individual participant data from extremely preterm infants recruited to large-scale trials to compare different oxygen saturation targets, confirmed that the lower oxygen saturation target (range $85-89 \%$ ) was associated with a lower risk of ROP treatment compared to the higher range (91-95\%), but a higher risk of mortality [26]. Although oxygen levels are important in the pathogenesis of ROP [27], finding a balance in oxygen delivery to ensure adequate levels for survival [26], and at the same time reducing the risk of ROP is not easy. In addition, recommended oxygen saturation levels in extremely low birth weight infants in the postnatal period remain unclear $[25,26]$. We found that CPAP was a safer way of oxygen administration in terms of ROP risk than nasal cannula as has been reported in some, but not all studies $[9,28]$. Differences in the characteristics of the study populations may explain the differences. On the other hand, the administration of CPAP already implicates a closer surveillance of these patients.

In our study only a combined variable of BW and GA remained significant in multivariate analysis and almost one in five babies with any ROP were beyond the 2013 American Academy screening guidelines for BW $(\leq 1500 \mathrm{~g})$ and GA ( $\leq 30$ weeks) [15]. The finding that larger and more mature infants are at risk of ROP is in accordance with studies from other middle income countries [5], suggesting that other modifiable risk factors play an important role in these settings.

In our study two babies with ROP exceeded one of the two study inclusion criteria ( $>1800 \mathrm{~g}$ BW or $>35$ weeks GA), but neither developed TW-ROP. Although screening of ROP can be a cause of stress to preterm infants and is resource intensive [19], this observation indicates that our wide inclusion criteria should not be narrowed in Rwanda.

Recently the US guidelines have considered slow weight gain as a risk factor [29]. Due to the lack of total parenteral feeding rapid weight gain rarely occurs in our study setting.

Future local audits analysing screening and treatment data can guide refinements to these screening criteria, if the characteristics of babies with TW-ROP change over time.

As in other studies $[9,10,22]$, sepsis was a significant risk factor for ROP. Perinatal inflammation might play a role in the pathogenesis of ROP due to changing levels of the cytokines involved in angiogenesis [30,31]. Although there is some variation depending on the definition of sepsis, rates can be high in NICUs with limited resources. However, even in low-income countries effective lowtechnology and low-cost nosocomial infection control strategies can be implemented successfully to tackle sepsis $[9,32]$. 
Table 2 Neonatal and clinical categorical data of the premature babies screened for retinopathy of prematurity $(n=424)$

\begin{tabular}{|c|c|c|c|c|c|c|c|c|c|c|c|c|}
\hline & \multicolumn{3}{|l|}{ All infants } & \multicolumn{3}{|l|}{ No ROP } & \multicolumn{3}{|l|}{ Any ROP } & \multicolumn{3}{|c|}{$\begin{array}{l}\text { Treatment- } \\
\text { warranted ROP }\end{array}$} \\
\hline & Missing data & $n$ & $\%$ & Missing data & $n$ & $\%$ & Missing data & $n$ & $\%$ & Missing data & $n$ & $\%$ \\
\hline Sepsis at some stage & 9 & & & 9 & & & & & & & & \\
\hline Based on clinical picture & & 214 & 51.6 & & 191 & 49.7 & & 23 & 74.2 & & 12 & 92.3 \\
\hline Confirmed by positive hemoculture & & 50 & 12.1 & & 47 & 12.2 & & 3 & 9.7 & & 1 & 7.7 \\
\hline No sepsis & & 151 & 36.4 & & 146 & 38.0 & & 5 & 16.1 & & 0 & 0.0 \\
\hline Timing of sepsis & 12 & & & 8 & & & 4 & & & 1 & & \\
\hline Early sepsis & & 133 & 52.8 & & 122 & 53.0 & & 11 & 50.0 & & 5 & 41.7 \\
\hline Late sepsis (after 3 postnatal days) & & 119 & 47.2 & & 108 & 47.0 & & 11 & 50.0 & & 7 & 58.3 \\
\hline Intraventricular haemorrhage at some stage & 8 & & & 8 & & & & & & & & \\
\hline Based on clinical picture & & 5 & 1.2 & & 5 & 1.3 & & 0 & 0.0 & & 0 & 0.0 \\
\hline Confirmed by ultrasound & & 7 & 1.7 & & 6 & 1.6 & & 1 & 3.2 & & 1 & 7.7 \\
\hline No intraventricular haemorrhage & & 404 & 97.1 & & 374 & 97.1 & & 30 & 96.8 & & 12 & 92.3 \\
\hline Necrotising enterocolitis at some stage & 8 & & & 8 & & & & & & & & \\
\hline Based on clinical picture & & 33 & 7.9 & & 29 & 7.5 & & 4 & 12.9 & & 1 & 7.7 \\
\hline Confirmed by X-ray & & 2 & 0.5 & & 2 & 0.5 & & 0 & 0.0 & & 0 & 0.0 \\
\hline No necrotising enterocolitis & & 381 & 91.6 & & 354 & 92.0 & & 27 & 87.1 & & 12 & 92.3 \\
\hline Patent ductus arteriosus & 8 & & & 8 & & & & & & & & \\
\hline Asymptomatic & & 30 & 7.2 & & 26 & 6.8 & & 4 & 12.9 & & 2 & 15.4 \\
\hline Hemodynamically significant & & 3 & 0.7 & & 3 & 0.8 & & 0 & 0.0 & & 0 & 0.0 \\
\hline No patent ductus arteriosus & & 383 & 92.1 & & 356 & 92.5 & & 27 & 87.1 & & 11 & 84.6 \\
\hline Glycemia & 273 & & & 257 & & & 16 & & & 8 & & \\
\hline Hyperglycaemia at some stage $(\geq 150 \mathrm{mg} / \mathrm{dl})$ & & 28 & 18.5 & & 20 & 14.7 & & 8 & 53.3 & & 1 & 20.0 \\
\hline No documented hyperglycaemia & & 123 & 81.5 & & 116 & 85.3 & & 7 & 46.7 & & 4 & 80.0 \\
\hline Total days on any supplemental oxygen & 11 & & & 11 & & & & & & & & \\
\hline None & & 134 & 32.4 & & 130 & 34.0 & & 4 & 15.4 & & 1 & 7.7 \\
\hline$<5$ days & & 130 & 31.5 & & 125 & 32.7 & & 5 & 16.1 & & 3 & 23.1 \\
\hline 5-9 days & & 56 & 13.6 & & 52 & 13.6 & & 4 & 12.9 & & 3 & 23.1 \\
\hline 10-24 days & & 53 & 12.8 & & 45 & 11.8 & & 8 & 25.8 & & 4 & 30.8 \\
\hline$\geq 25$ days & & 40 & 9.7 & & 30 & 7.9 & & 10 & 32.3 & & 2 & 15.4 \\
\hline Received blood transfusion & 8 & & & 8 & & & & & & & & \\
\hline None & & 299 & 71.9 & & 285 & 74.0 & & 14 & 45.2 & & 6 & 46.2 \\
\hline Once & & 75 & 18.0 & & 62 & 16.1 & & 13 & 41.9 & & 7 & 53.8 \\
\hline Multiple & & 42 & 10.1 & & 38 & 9.9 & & 4 & 12.9 & & 0 & 0.0 \\
\hline
\end{tabular}

$R O P$ retinopathy of prematurity

By prospectively recruiting all consecutive preterm infants born in the three major NICUs, we analysed a representative sample of the prematurely born baby population of tertiary medical centres in Rwanda. However, during the 2-year study neonatal care was introduced in several peripheral district hospitals, and ophthalmology departments witnessed an increasing number of preterm infants admitted for ROP treatment who had received care outside our study centres. Therefore, the incidence of ROP in our study may not reflect the overall incidence. This observation also suggests that the epidemic of ROP has only just begun in Rwanda and that screening needs to be expanded to these peripheral hospitals as well. Remote ROP screening using high-resolution widefield imaging systems, with interpretation of the images at an off-site reading centre, would be one way to expand coverage, as has been implemented with success in middle and highincome countries with a shortage of eye healthcare professionals [33]. Recently the application of less expensive systems and even smartphones (iPhone 5 combined with 20D lens) have been described for ROP-screening [34]. This telemedicine approach might be an option for Rwanda, but care should be taken to train the photographers well, since visualising the peripheral retina, which is of vital importance in ROP screening, can be challenging. 


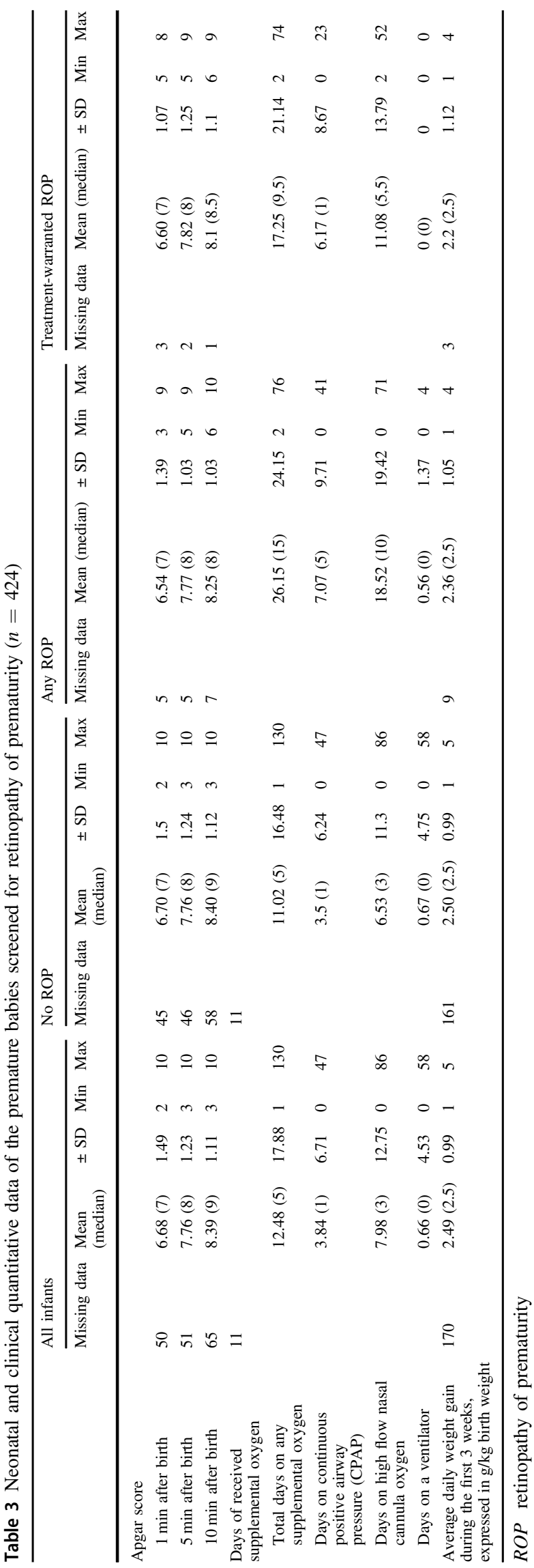

Table 4 Univariate logistic regression analyses of risk factors in relation to development of any retinopathy of prematurity (ROP) versus no ROP among 424 screened premature babies $(n=424)$

\begin{tabular}{|c|c|c|c|}
\hline \multirow[t]{2}{*}{ Risk factors } & \multicolumn{3}{|l|}{ Any ROP } \\
\hline & Odds ratio & $\begin{array}{l}95 \% \\
\text { Confidence } \\
\text { interval }\end{array}$ & $P$-value \\
\hline Maternal age $<25$ years & 0.98 & $0.36-2.72$ & 0.97 \\
\hline Positive HIV status mother & 0.00 & & 0.5 \\
\hline Received antenatal steroid & 1.15 & $0.52-2.53$ & 0.72 \\
\hline Primipara & 0.62 & $0.26-1.48$ & 0.28 \\
\hline Multiple birth gestation & 0.78 & $0.32-1.86$ & 0.57 \\
\hline Caesarean section & 0.48 & $0.23-1.00$ & 0.05 \\
\hline Birth place outside NICU-hospital & 2.26 & $0.92-5.58$ & 0.07 \\
\hline Male gender & 0.72 & $0.34-1.53$ & 0.4 \\
\hline \multicolumn{4}{|c|}{ Prematurity (gestational age in weeks) } \\
\hline Dose-response effect & 3.41 & $1.81-6.41$ & $<0.001$ \\
\hline$<28$ & 5.90 & $1.38-25.14$ & 0.006 \\
\hline 28 to $<32$ & 4.37 & $1.84-10.35$ & $<0.001$ \\
\hline$\geq 32$ & Baseline & & \\
\hline \multicolumn{4}{|l|}{ Low birth weight $(\mathrm{g})$} \\
\hline Dose-response effect & 2.25 & $1.48-3,41$ & $<0.001$ \\
\hline$<1000$ & 26.78 & $2.59-277.31$ & $<0.001$ \\
\hline 1000 to $<1500$ & 7.04 & $0.90-55.23$ & 0.03 \\
\hline 1500 to $<1800$ & 4.24 & $0.49-36.54$ & 0.15 \\
\hline$\geq 1800$ & Baseline & & \\
\hline $\begin{array}{l}\text { Low Apgar score } 5 \text { min after birth } \\
(<7)\end{array}$ & 0.59 & $0.13-2.59$ & 0.48 \\
\hline Sepsis at some stage & 3.19 & $1.19-8.56$ & 0.01 \\
\hline $\begin{array}{l}\text { Intraventricular haemorrhage at } \\
\text { some stage }\end{array}$ & 1.13 & $0.14-9.10$ & 0.91 \\
\hline $\begin{array}{l}\text { Necrotising enterocolitis at } \\
\text { some stage }\end{array}$ & 1.69 & $0.55-5.16$ & 0.35 \\
\hline Patent ductus arteriosus & 1.82 & $0.59-5.57$ & 0.29 \\
\hline $\begin{array}{l}\text { Hyperglycaemia }(\geq 150 \mathrm{mg} / \mathrm{dl}) \text { at } \\
\text { some stage }\end{array}$ & 6.63 & $2.04-21.50$ & $<0.001$ \\
\hline \multicolumn{4}{|c|}{ Daily weigth gain at 3th week per kg birth weight } \\
\hline $12 \mathrm{~g}<$ loss $<0$ g per day & 1.95 & $0.45-8.47$ & 0.36 \\
\hline $0 \mathrm{~g} \leq$ gain $<5 \mathrm{~g}$ per day & 0.89 & $0.20-3.94$ & 0.88 \\
\hline $5 \mathrm{~g} \leq$ gain $<10$ g per day & 1.42 & $0.35-5.70$ & 0.62 \\
\hline Gain $\geq 10 \mathrm{~g}$ per day & Baseline & & \\
\hline $\begin{array}{l}\text { Received blood transfusion at } \\
\text { some stage }\end{array}$ & 3.46 & $1.63-7.36$ & $<0.001$ \\
\hline \multicolumn{4}{|l|}{ Received supplemental oxygen } \\
\hline $\begin{array}{l}\text { Continuous positive airway } \\
\text { pressure (CPAP) at some stage }\end{array}$ & 0.82 & $0.37-1.83$ & 0.63 \\
\hline Ventilator at some stage & 5.30 & $1.45-19.37$ & 0.005 \\
\hline \multicolumn{4}{|c|}{ Days on high flow nasal cannula oxygen } \\
\hline$<6$ days & Baseline & & \\
\hline $6-16$ days & & $0.56-5.13$ & 0.35 \\
\hline 17-86 days & 5.83 & $2.24-15.22$ & $<0.001$ \\
\hline Dose-response effect & 2.87 & $1.68-4.91$ & $<0.001$ \\
\hline \multicolumn{4}{|l|}{ Total days on any supplemental oxygen } \\
\hline$<5$ days & Baseline & & \\
\hline 5-9 days & 1.92 & $0.49-7.50$ & 0.34 \\
\hline 10-24 days & 4.44 & $1.35-14.68$ & 0.007 \\
\hline$\geq 25$ days & 8.33 & $2.48-27.96$ & $<0.001$ \\
\hline Dose-response effect & 2.13 & $1.49-3.04$ & $<0.001$ \\
\hline
\end{tabular}

$R O P$ retinopathy of prematurity 
There are some limitations in our study. For example, loss to follow-up, which was in line with other studies from sub-Saharan Africa [9], may have biased the findings, particularly as those not followed up were born with a lower BW than those who were screened. Although there were no medical costs and transport costs were reimbursed, $17.1 \%$ of infants had insufficient screening episodes to ascertain the occurrence of ROP. Difficulties in completing screening following discharge from the NICU have been encountered in other communities [35, 36]. Further sensitisation of parents and health community on the importance of ROP screening is mandatory to reduce loss to follow-up. Screening before discharge from NICU even if the screening was not yet due, streamlined scheduling, and creation of a log for all patients seen, can improve follow-up after discharge [36, 37].

Despite offering training and follow-up sessions and the use of standard photographs on ROP-classification, some degree of inter-observer variability and observer bias/measurement error between the study ophthalmologists cannot be ruled out, especially for the clinically milder stages of ROP. Furthermore, assessing the zone of vascularisation is difficult and ceasing screening when vessels have entered zone III might not be safe [38].

In conclusion, like in other low and middle-income countries, ROP has become an emerging health problem in Rwanda. It is expected that with further economic progress and consequently improved neonatal care, more babies will survive and hence develop ROP in sub-Saharan Africa [12]. Screening for ROP is indicated beyond the criteria recommended in the 2013 American Academy screening guidelines [15]. Identification of several potentially modifiable risk factors allows Ministries of Health and other organisations involved in neonatal care and the prevention of blindness in children in sub-Saharan Africa, to direct their efforts to improve neonatal care and establish screening and treatment for ROP.

\section{Summary}

\section{What was known before}

- ROP is a public health problem in middle-income countries in Asia and Latin America and some countries in South and West Africa.

\section{What this study adds}

- Although rarely seen a decade before, ROP has now become an important cause of visual impairment in other African countries like Rwanda, requiring programmes for screening and treatment.

- ROP screening is indicated beyond the 2013 American Academy guidelines in this setting.

Acknowledgements The authors would like to acknowledge the members of the Rwanda Retinopathy of Prematurity (ROP) Study Group for their valuable contribution to this study (alphabetical order): Cannoodt Luk, PhD, Health Policy Analyst, KU Leuven (Belgium), NGO Umubano-Impore; Casteels Ingele, MD, PhD, Paediatric Ophthalmologist, KU Leuven, Belgium; Conard Craig, MD, MPH, Paediatrician CHUB; De Smedt Stefan, MD, PhD, ophthalmologist/epidemiologist, AZ St Maarten, Mechelen, Belgium; Devlieger Hugo, MD, PhD, neonatologist, KU Leuven, Belgium; Fonteyne Yannick, MD; Gilbert Clare, $\mathrm{MD}, \mathrm{PhD}$, International Centre for Eye Health, London School of Hygiene and Tropical Medicine, London, UK; Gisagara Egide, MD, ophthalmologist ; Kumwami Muzungu, MD, paediatrician CHUK; Mudereva Godelieve, MD, ophthalmologist CHUK; Muhizi Charles, MD, ophthalmologist CHUB; Mulindwa Karemazi Gustave, MD, paediatrician CHUB; Musiime Stephenson, MD, FCPaeds(SA), paediatrician KFH; Mutangana Francis, MD, ophthalmologist KFH; Mutsinzi Edison, MD, ophthalmologist Kabgayi Eye Unit; Ngambe Tharcisse, MD, paediatrician KFH; Noë Piet, MD, ophthalmologist Kabgayi Eye Unit, Rwanda Charity Eye Hospital; Nsabimana Hovaire, MD, paediatrician CHUB; Nyemazi Alex, MD, ophthalmologist KFH; Sebuseruka Sonia, MD, ophthalmologist; Tuyisabe Theophile, MD, ophthalmologist Kabgayi Eye Unit; Tuyisenge Lisine, MD, paediatrician CHUK; Uwurukundo Marie Claude, MD, paediatrician KFH; Van Kerschaver Erwin, MD PhD.

Funding Hoffknecht Van Vuure Stichting (The Netherlands), Vision for All (Switzerland), Rotary Club Overijse Zonienwoud (Belgium), Lions Club Heerlijkheid Mechelen (Belgium), Lumos University Hospitals Leuven (Belgium), Théa Pharma, NGO Umubano- Impore (Rwanda). The funding organizations had no role in the design or conduct of this research.

Rwanda Retinopathy of Prematurity (ROP) Study Group Luk Cannoodt $^{11}$, Ingele Casteels ${ }^{9}$, Craig Conard ${ }^{7}$, Stefan De Smedt ${ }^{10}$, Hugo Devlieger ${ }^{12}$, Yannick Fonteyne ${ }^{8}$, Clare Gilbert ${ }^{13}$, Egide Gisagara $^{3}$, Muzungu Kumwami ${ }^{6}$, Godelieve Mudereva ${ }^{3}$, Charles Muhizi $^{2}$, Gustave Mulindwa Karemazi ${ }^{7}$, Stephenson Musiime ${ }^{5}$, Francis Mutangana ${ }^{1}$, Edison Mutsinzi ${ }^{14}$, Tharcisse Ngambe ${ }^{5}$, Piet Noë ${ }^{15}$, Hovaire Nsabimana ${ }^{7}$, Alex Nyemazi ${ }^{1}$, Sonia Sebuseruka ${ }^{16}$, Theophile Tuyisabe $^{14}$, Lisine Tuyisenge ${ }^{6}$, Marie Claude Uwurukundo ${ }^{5}$, Erwin Van Kerschaver

${ }^{11}$ Health Policy Analist, NGO Umubano-Impore, KU Leuven, Leuven, Belgium; ${ }^{12}$ Pediatrics, KU Leuven, Leuven, Belgium; ${ }^{13}$ International Centre for Eye Health, Department of Clinical Research, London School of Hygiene and Tropical Medicine, London, UK; ${ }^{14}$ Ophthalmology, Kabgayi Eye Unit, Muhanga, Rwanda; ${ }^{15}$ Ophthalmology, Kabgayi Eye Unit, Rwanda Charity Eye Hospital, Southern Province, Rwanda; ${ }^{16}$ Ophthalmology, Kigali, Rwanda

\section{Compliance with ethical standards}

Conflict of interest The authors declare that they have no conflict of interest. 
Publisher's note: Springer Nature remains neutral with regard to jurisdictional claims in published maps and institutional affiliations.

\section{References}

1. Chan-Ling T, Gole GA, Quinn GE, Adamson SJ, Darlow BA. Pathophysiology, screening and treatment of ROP: a multidisciplinary perspective. Prog Retin Eye Res. 2018;62:77-119.

2. Gilbert C, Rahi J, Eckstein M, O'Sullivan J, Foster A. Retinopathy of prematurity in middle-income countries. Lancet. 1997;350:12-4.

3. Blencowe H, Lawn JE, Vazquez T, Fielder A, Gilbert C. Pretermassociated visual impairment and estimates of retinopathy of prematurity at regional and global levels for 2010. Pedia Res. 2013;74(Suppl 1):35-49.

4. Quinn G, Gilbert C, Darlow B, Zin A. Retinopathy of prematurity: an epidemic in the making. Chin Med J. 2010;123:2929-37.

5. Gilbert C, Fielder A, Gordillo L, Guinn G, Semiglia R, Zin A, et al. Characteristics of infants with severe retinopathy of prematurity in countries with low, moderate and high levels of development: implications for screening programs. Pediatrics. 2005;115:e518-e25.

6. Gilbert CE. Screening for retinopathy of prematurity: does one size fit all? Arch Dis Child Fetal Neonatal Ed. 2016;101:F280-1.

7. Delport S, Swanepoel J, Odendaal P, Roux P. Incidence of retinopathy of prematurity in very low birth weight infants born at Kalafong Hospital, Pretoria. S Afr Med J. 2002; 92:986-90.

8. Kirsten G, Van Zyl J, Le Grange M, Ancker E, Van Zyl F. The outcome at 12 months of very-low-birth-weight infants ventilated at Tygerberg Hospital. S Afr Med J. 1995;85:649-54.

9. Keraan Q, Tinley C, Horn A, Pollock T, Steffen J, Joolay Y. Retinopathy of prematurity in a cohort of neonates at Groote Schuur Hospital, Cape Town, South Africa. S Afr Med J. 2016;107:64-9.

10. Van der Merwe SK, Freeman N, Bekker A, Harvey J, Smith J. Prevalence of and risk factors for retinopathy of prematurity in a cohort of preterm infants treated exclusively with non-invasive ventilation in the first week after birth. S Afr Med J. 2013;103:96-100.

11. Fajolu IB, Rotimi-Samuel A, Aribaba OT, Musa KO, Akinsola FB, Ezeaka VC, et al. Retinopathy of prematurity and associated factors in Lagos, Nigeria. Paediatr Int Child Health. 2015;35:324-8.

12. Mora JS, Waite C, Gilbert CE, Breidenstein B, Sloper JJ. A worldwide survey of retinopathy of prematurity screening. Br J Ophthalmol. 2018;102:9-13.

13. Ntigurirwa $\mathrm{P}$, Mellor $\mathrm{K}$, Langer D, Evans $\mathrm{M}$, Robertson $\mathrm{E}$, Tuyisenge L, et al. A health partnership to reduce neonatal mortality in four hospitals in Rwanda. Glob Health. 2017;13:28.

14. International Committee for the Classification of Retinopathy of Prematurity. The International Classification of Retinopathy of Prematurity revisited. Arch Ophthalmol. 2005;123:991-9.

15. Section on Ophthalmology, American Academy of Pediatrics, American Academy of Ophthalmology, American Association for Pediatric Ophthalmology, Strabismus. Screening examination of premature infants for retinopathy of prematurity. Important changes from 2006 criteria are noted including new recommendations for selective earlier screening, treatment, and follow-up after discharge from the NICU. Pediatrics. 2013;131:189-95.

16. O'Sullivan J, Gilbert C, Foster A. The causes of childhood blindness in South Africa. S Afr Med J. 1997;87:1691-5.

17. Baiyeroju-Agbeja AMOS. Screening for retinopathy of prematurity in Ibadan. Niger J Ophthalmol. 1998;6:23-5.
18. Jacoby MR, Du Toit L. Screening for retinopathy of prematurity in a provincial hospital in Port Elizabeth, South Africa. S Afr Med J. 2016;106:598-601.

19. Visser Kift E, Freeman N, Cook C, Myer L. Retinopathy of prematurity screening criteria and workload implications at Tygerberg Children's Hospital, South Africa: a cross-sectional study. S Afr Med J. 2016;106:602-6.

20. Adio AO, Ugwu RO, Nwokocha CG, Eneh AU. Retinopathy of prematurity in Port Harcourt, Nigeria. ISRN Ophthalmol. 2014: $1-6$.

21. Howson CP, Kinney MV, McDougall L, Lawn JE. Born too soon: preterm birth matters. Reprod Health. 2013;10(Suppl 1):S1.

22. Goncalves E, Nasser LS, Martelli DR, Alkmim IR, Mourao TV, Caldeira AP, et al. Incidence and risk factors for retinopathy of prematurity in a Brazilian reference service. Sao Paulo Med J. 2014;132:85-91.

23. Rao KA, Purkayastha J, Hazarika M, Chaitra R, Adith KM. Analysis of prenatal and postnatal risk factors of retinopathy of prematurity in a tertiary care hospital in South India. Indian J Ophthalmol. 2013;61:640-4.

24. Vinekar A, Jayadev C, Kumar S, Mangalesh S, Dogra MR, Bauer $\mathrm{NJ}$, et al. Impact of improved neonatal care on the profile of retinopathy of prematurity in rural neonatal centers in India over a 4-year period. Eye Brain. 2016;8:45-53.

25. Sweet DG, Carnielli V, Greisen G, Hallman M, Ozek E, Plavka R, et al. European Consensus Guidelines on the management of respiratory distress syndrome-2016 update. Neonatology. 2017;111:107-25.

26. Askie LM, Darlow BA, Finer N, Schmidt B, Stenson B, TarnowMordi W, et al. Association between oxygen saturation targeting and death or disability in extremely preterm infants in the Neonatal Oxygenation Prospective Meta-analysis Collaboration. JAMA. 2018;319:2190-201.

27. Liegl R, Hellstrom A, Smith LE. Retinopathy of prematurity: the need for prevention. Eye Brain. 2016;8:91-102.

28. Arima M, Tsukamoto S, Fujiwara K, Murayama M, Fujikawa K, Sonoda KH. Late-onset circulatory collapse and continuous positive airway pressure are useful predictors of treatmentrequiring retinopathy of prematurity: a 9-year retrospective analysis. Sci Rep. 2017;7:3904.

29. Binenbaum G, Bell EF, Donohue P, Quinn G, Shaffer J, Tomlinson LA, et al. Development of modified screening criteria for retinopathy of prematurity: primary results from the Postnatal Growth and Retinopathy of Prematurity Study. JAMA Ophthalmol. 2018;136:1034-40.

30. Sood BG, Madan A, Saha S, Schendel D, Thorsen P, Skogstrand $\mathrm{K}$, et al. Perinatal systemic inflammatory response syndrome and retinopathy of prematurity. Pedia Res. 2010;67:394-400.

31. Silveira RC, Fortes Filho JB, Procianoy RS. Assessment of the contribution of cytokine plasma levels to detect retinopathy of prematurity in very low birth weight infants. Invest Ophthalmol Vis Sci. 2011;52:1297-301.

32. Landre-Peigne $\mathrm{C}$, Ka AS, Peigne V, Bougere J, Seye MN, Imbert P. Efficacy of an infection control programme in reducing nosocomial bloodstream infections in a Senegalese neonatal unit. J Hosp Infect. 2011;79:161-5.

33. Dogra MR, Katoch D, Dogra M. An update on Retinopathy of Prematurity (ROP). Indian J Pediatr. 2017;84:930-6.

34. Oluleye TS, Rotimi-Samuel A, Adenekan A. Mobile phones for retinopathy of prematurity screening in Lagos, Nigeria, subSaharan Africa. Eur J Ophthalmol. 2016;26:92-4.

35. Aprahamian AD, Coats DK, Paysse EA, Brady-Mccreery K. Compliance with outpatient follow-up recommendations for infants at risk for retinopathy of prematurity. J aapos. 2000;4:282-6.

36. Barry GP, Tauber K, Emmanuel G, Horgan MJ, Simon JW. The effectiveness of policy changes designed to increase the 
attendance rate for outpatient retinopathy of prematurity (ROP) screening examinations. J AAPOS. 2013;17:296-300.

37. Vinekar A, Jayadev C, Dogra M, Shetty B. Improving follow-up of infants during retinopathy of prematurity screening in rural areas. Indian Pediatr. 2016;53(Suppl 2):S151-s4.
38. Campbell JP, Ryan MC, Lore E, Tian P, Ostmo S, Jonas K, et al. Diagnostic discrepancies in retinopathy of prematurity classification. Ophthalmology. 2016;123:1795-801. 